\title{
Scientists and deliberativeness of European public television news
}

\author{
Richard van der Wurff, Piet Verhoeven and Maite Gadellaa
}

\begin{abstract}
Scientists intermittently appear on television news as experts to inform and comment on current events. This study explores whether their appearance adds a critical measure of substantiated arguments and balanced judgements to public affairs reporting. An explorative analysis of a representative sample of news broadcasts from five public broadcasters in Western Europe in 2006 and 2007 suggests that this is to some extent the case. The implications of these findings for the deliberative quality of TV news are discussed, and a typology of scientific experts in the general news items is proposed.
\end{abstract}

\section{Introduction}

"In science there are always many sides... the trouble with journalism is you only have space for two sides". ${ }^{1}$

Personal experience and research tell us that scientists intermittently appear on television news as experts. They inform and comment on social, policy, medical and scientific issues. ${ }^{2}$ This is an important though under-investigated aspect of science communication. Intuitively, we might hope that these scientists add a necessary dose of science-based arguments and substantiated judgements to television news. But available studies, both on TV news and science communication - for which television still is regarded as the number one medium ${ }^{3}$ — point in a different direction.

Studies that focus on science news present scientists and journalists as two distinct professional groups with contrasting professional cultures. ${ }^{4}$ They think differently about the appropriate shape and content of science news items. Scientists - a term we use inclusively to denote a varied set of academically trained scholars with backgrounds in the natural and social sciences as well as the humanities - supposedly aim for a serious and scientific style in which complex matters are unravelled and accurately explained, remaining uncertainties acknowledged, and ideas not too quickly taken for granted. Ideally, scientists would contribute a critical measure of scientific expertise, dissonant ideas, substantiated arguments, independent reflexivity and balanced judgements to public affairs reporting. ${ }^{5}$

Of course, scientists also have their own interests and concerns for media attention. ${ }^{6}$ For example, they can be personally, normatively or intellectually motivated to be 
involved in politics or social issues outside academia. ${ }^{7}$ Or they aim, steered by their institutional background, to increase awareness of their institution (e.g., a university), to position it on the market, and to obtain research funding or influence policy. ${ }^{8}$ In addition, scientists are increasingly trained to deal with and speak for media, so that they better equipped to accomplish their aims ${ }^{9}$.

Journalists, in turn, have become more inclined to use entertaining elements and formats in order to reach and subsequently inform audiences, ${ }^{10}$ also when reporting about science. ${ }^{11}$ Especially in the current media environment, entertaining elements and attractive angles are routinely included in TV news to draw audiences on competitive media markets. As a result, scientists may be embedded in a media logic that demands TV news to be personalized, unambiguous and easily told, and that leaves little room for factual or deliberative elaborations.

Illustrating these different approaches, scientists believe that they should restrict themselves to their narrow field of expertise when appearing in news items. ${ }^{12}$ This fits academic interpretations of expertise as a thorough understanding of a particular field based at least partly on own research. ${ }^{13}$ Yet, already in 1981, almost a third of scientists contacted by journalists were asked to discuss topics that were at best tangentially related to their own work. ${ }^{14}$ Albaek and colleagues found 20 years later that the range of issues on which experts (seemingly) credibly can comment, has widened considerably in the last decades, especially for generalists with a social science or humanities background. ${ }^{15}$

These findings raise questions to what extent scholars can play a role as science communicators when they appear in general news items, by adding a critical measure of science-based arguments and judgements on a public interest issue.

To investigate this issue, we explore the following research question: Do scientists contribute diverse viewpoints and substantiated arguments to TV news items? We investigate this question with an explorative content analysis of a representative sample of news broadcasts from five public broadcasters in Western Europe in 2006 and 2007.

\section{Context}

We focus on television news, because it is an important source of current affairs information for the general audience, as well as the preferred medium for science communication. ${ }^{16}$ Eurobarometer surveys consistently show that people in Europe depend on television as the prime and trusted source for their daily news on political matters. ${ }^{17}$ For example, $77 \%$ of the Dutch population identified in 2011 the public TV news cast as one of their favourite news sources. ${ }^{18}$

But the informative quality of television news is questioned. Generally speaking, communication scholars believe that citizens learn more from newspapers than television. ${ }^{19}$ Of course, differences within these categories exist. Audiences learn more from public than from commercial TV news, ${ }^{20}$ and tabloid newspapers are less informative than public TV news. ${ }^{21}$ Nevertheless, the media logic of TV is generally considered to be at odds with in-depth and background information. TV thrives on emotions, incidents, and clear-cut conflicts. There is little room for the deliberative 
elaboration of positions and reasoned debates in which arguments and counterarguments are made and learning can take place. $^{22}$

This is unfortunate, because the deliberative quality of news items is important for modern democracies. ${ }^{23}$ Media content should reflect different opinions, even confront audiences with dissenting ideas, in order to stimulate debate and innovative thinking, and to empower citizens to make political choices. ${ }^{24}$ Quality deliberation moreover requires that multiple perspectives are argued and compared; that claims are justified, that competing claims are criticized and that counterclaims are rebutted. ${ }^{25}$ Perhaps scientists are well positioned to improve the deliberative quality of television news items in which they appear as experts?

Scientists in the news. Actually, we do not know much about the role of scientists in general interest news. What we do know is that journalists increasingly tend to give scientists a role as expert. ${ }^{26}$ Albaek, Christiansen and Togeby report two interesting trends in this respect. ${ }^{27}$ First, the number of articles in Danish national newspapers citing scientists has increased sevenfold between 1961 and 2000. Second, these scholars increasingly have a social science background and comment on social and policy issues, instead of merely communicating discoveries in science and medicine. ${ }^{28}$

These trends reflect the growing dependency of society, and journalists, on expert knowledge. They also illustrate that scholars are increasingly aware that media attention pays in terms of attracting funding. ${ }^{29}$ This incentive adds to scientists' longstanding normative and intellectual motivations for political and social involvement. ${ }^{30}$

\section{Science news}

Empirical research on the role of science in the media shows consistently that science does not get much attention in newspapers ${ }^{31}$ or other news media. ${ }^{32}$ For example, studies consistently show that only a minor part of news items deal with science and technology. Findings range from 0.1 item per news program in Western Europe, ${ }^{33} 2.4 \%$ of the news items in the most important news programs in five Western European countries, ${ }^{34}$ and $7.3 \%$ in the Brazilian newscast Journal Nacional. ${ }^{35}$ These news items about science are usually longer than other topics. ${ }^{36}$ Attention to science and technology in news programs thus varies per country. ${ }^{37}$

Science news is often about scientific breakthroughs and concrete events, ${ }^{38}$ elite groups of scientists, ${ }^{39}$ and conflicts and controversies in society or in the scientific world. $^{40}$ In reporting about science the media prefer unambiguity, ${ }^{41}$ simplification and symbolisation, ${ }^{42}$ and sometimes dissident scientists. ${ }^{43}$ Most attention is paid to the natural sciences, medicine and technology. ${ }^{44}$

Science news - we may conclude - tend to popularise science and emphasize the positive consequences of scientific discoveries for improving human lives; or focus on the risks and possible negative consequences of scientific discoveries and on the resulting controversies in society. Some media, though, give niche audiences 
background information about science in special science sections of newspapers ${ }^{45}$ or in special television programs dedicated to science and scientific developments. ${ }^{46}$

Scientists as sources. Research shows that scientists can be attractive sources in science news items. Like general news reporters, science reporters seek knowledgeable, articulate, accessible and, if possible, prestigious sources and experts to provide (background) information and perspective to scientific discoveries. These experts may be scientists directly involved in a study or their administrators, but also include other scientists - that may or may not have specific expertise in the area that is covered. Reporters embed these sources to provide scientific and social context to a study, underline its reliability, address its implications and, if necessary, criticize a study or add a cautionary note. ${ }^{47}$

Overall, these findings mirror what we know about the role of sources in general. Sources need to be accessible and reliable, able to provide suitable information, radiate authority and trustworthiness, and be articulate. ${ }^{48}$ This means that not only the power and influence of the source are important. Also its public relations and news management efforts and the mutual self interest of sources (and journalists) in news coverage play a role. ${ }^{49}$

A clash between cultures. The interactions between journalists and scientists are confounded by differences in professional culture and conceptualisations of news quality that result in a struggle for control over science news items. ${ }^{50}$ Scientists emphasize that reporting should be objective and unbiased, non-emotional and not sensationalized, sober and matter-of-factly, and "oriented towards the scientific truth". ${ }^{51}$ A large scale survey among scientists in the UK and US shows that scientists in general are critical of media coverage of science. But they judge their own experience with journalists more positively. ${ }^{52}$

Journalists are inclined to put emphasis on the societal functions of journalism. They emphasize that stories should be informative and attractive for readers, and focus on social and political issues and interpretations. ${ }^{53}$ They also have time and space constraints which put them in a different position than scientists. ${ }^{54}$

Consider for example the press coverage of cloning, on the occasion of the birth of Dolly, a cloned sheep. Studies show considerable tension between scientists and journalists on how this issue should be reported. Scientists were interested in disseminating scientific information. Journalists, on the other hand, were more interested in the cultural aspects of cloning. ${ }^{55}$ They introduced ethical considerations in the debate about cloning in the USA, ${ }^{56}$ and influenced the political and societal debate in the UK. ${ }^{57}$

These different approaches put the quality of reporting about the scientific aspects of social issue at risk. Journalistic reporting on French TV does not adequately reflect the evolution of scientific knowledge about a disease like the Attention Deficit Hyperactivity Disorder (ADHD) ${ }^{58}$ and rhetorical practices of journalists changed the interpretation of consumer information on contamination in farmed salmon in the US. ${ }^{59}$ 
These and other studies indicate that there is a gap between the two professions, ${ }^{60}$ with journalistic conceptualisations of news quality gradually overruling scientific ones. $^{61}$ Science-centred items, dominated by experts proclaiming scientific findings, have given way to journalist-centred formats of reporting in which journalists are the main protagonists that inform the public in a more or less entertaining way. ${ }^{62}$ This reminds us of similar developments in political news where journalists embed sources to tell attractive stories. ${ }^{63}$

\section{Media logic}

The shift towards more mediated, journalist-centred forms of reporting reflects the growing dominance of a modern media-logic that demands entertainment, personalization, news values, and a reduction of ambiguity. ${ }^{64}$ In medical programmes, attention shifts from ordinary ailments to high-tech medical issues with limited practical relevance but high attention value. Experts recede into the background where they are represented as archetypical doctors in white coats. Less time is spent on elucidating case-transcending scientific backgrounds and explanations. Rather, individual patients - and more recently celebrity patients - take centre stage with their personal characteristics, personalized problems and hands-on experiences. ${ }^{65}$ Michelle refers to this as "anecdotal personalization", a type of human interest framing that emphasizes potential benefits of medical technology for individuals and diverts attention away from potential risks and broader social, ethical, economic and political questions. ${ }^{66}$ But also a shift in emphasis to fears and panic in society rather than research and scientific development is feasible, as was observed in media reports about the new disease H1N1 in 2009 in Brazil. ${ }^{67}$ Also such a shift results in an emphasis on news values (negativity, threat) that fit the modern media logic.

An interesting case study by Steele indicates what the shift towards journalistcentred formats and the rise of media logic might imply for the quality of reporting. ${ }^{68}$ In line with television news' "operational bias", ${ }^{69}$ journalists reporting on the Persian Gulf War (1990-91) for US TV news looked for 'leading' experts with 'real world' experience, who knew how to speak on television and who were willing to make predictions ("What is the best the U.S. can hope for from the B-52 campaign against the Republican Guard?"70) or second-guess the motives and strategies of players. Especially former public officials, retired military and think tank analysts met this description. But also academics appeared in the news, e.g., to predict the economic impact of the war, to forecast gasoline prices, and to speculate on Saddam Hussein's motives. With hindsight, TV routines resulted in a rather limited selection of familiar experts who contributed to a biased, narrow and instantaneous reporting "that failed to place events in a broader historical, economic, social context". ${ }^{71}$

\section{News frames}

The deliberative quality of news items is related to the news frame adopted by journalists. Following the suggestions of De Vreese ${ }^{72}$ and Tewksbury et al., ${ }^{73}$ we define 
journalistic news frames as the structural and organizational, and thus issueoverarching, conventions of how issues are presented in attractive and newsworthy stories. These should be distinguished from issue specific advocacy frames that express the views of contending social actors on particular issues and "promote a particular problem definition, causal interpretation, moral evaluation, and/or treatment recommendation". ${ }^{74}$

Important for our analysis is Iyengar's distinction between episodic and thematic news frames. ${ }^{75}$ Episodic frames are journalistic frames that present issues as "specific instances" or relatively isolated events, whereas thematic frames place issues "in some appropriate context — historical, geographical or otherwise". ${ }^{76}$ Thematic frames make a better presentation of diverse ideas and arguments possible than episodic frames but TV news stories are overwhelmingly characterized by the episodic frame. ${ }^{77}$

Semetko and Valkenburg add that journalists, in presenting an issue, generally can choose between conflict frames (emphasizing power struggles or conflicts of opinion, responsibility frames (emphasizing actors' responsibilities), economic consequences frames (stressing costs), human interest frames, or morality frames (highlighting moral questions), as different ways to increase story appeal. ${ }^{78}$ In Dutch TV news, responsibility, conflict and human interest are the most prevalent. ${ }^{79}$

A shared finding emerging from available studies is that news items generally present only one or two competing issue frames. Journalists tend to reduce controversies at best to "two competing packages - an official one and (if there is one) the alternative sponsored by the most vested member of the polity". ${ }^{80}$ Conflict frames, in particular, "reduce complex substantive debate to simplistic two-sided competition". ${ }^{81}$

TV news frames. Cottle and Rai studied the frames and argumentative characteristics of a cross-national sample of 9662 TV news items broadcasted in September $2004 .^{82}$ They found that by far the most items $(59 \%)$ belong to what they call the classical reporting frame. These items merely provide facts and "thin accounts of events", ${ }^{83}$ without much background or competing viewpoints. Much smaller proportions of items only present the dominant view on a contentious issue $(12 \%)$, provide a consensual view on less contentious issues (14\%), or frame an issue as a binary opposition between two views $(6 \%)$.

Closest to a scholarly perspective comes the contention frame ( $6 \%$ of items). Items organized around this frame present "a plurality of voices/perspectives [...] [that] do not take the form of a diametric opposition, but rather represent something of the complexity of positions and points of view [...]". ${ }^{84}$ Also providing room for quality deliberation is the reportage frame (similar to the thematic frame, and found in $3 \%$ of items), which provides "detailed background, context and analysis" and generates "indepth understanding". 85

Together, these studies show that TV news items overwhelmingly focus on events (episodic framing), and emphasize mostly one but sometimes two conflicting views. Just a small proportion provides a more in-depth account of issues. 
Also frames used in reports about science are sometimes polarized and dramatic for example in the case of the representation of the human-elephant conflict in Indian and international media; ${ }^{86}$ sometimes predominantly positive - as in the case of nanotechnology in the German press; ${ }^{87}$ and sometimes more varied, nuanced and differentiated - as found in studies of several aspects of the debates in various countries about biotechnology, ${ }^{88}$ genetics, ${ }^{89}$ or environmental issues like climate change. $^{90}$

\section{Framing of experts}

One final aspect to be discussed is the framing of experts and the related construction of expertise in news items. Above, we already discussed that journalists might stress the 'real world' hands-on experience of sources in order to underline their authority to audiences. Likewise, journalists tend to emphasize institutional affiliation when introducing sources. ${ }^{91}$ But scholars and experts are primarily framed in stereotyped roles.

Schnabel described two types of exaggerated stereotypes that journalists use to describe scientists: heroes that bring 'Gods formula' down to earth, and fallen angels whose science has turned into something evil and frightening. ${ }^{92}$ Väliverronen elaborates that framing of experts and the construction of expertise varies with the (issue) framing of a news item. ${ }^{93}$ When journalists on Finnish TV news frame biotechnology in terms of economic opportunities and international competitiveness, scientists are accordingly positioned as "neutral experts explaining the needs of their research community or as heroes running in the forefront of research". ${ }^{4}$ Other positions occupied by scientists include the role of healer in a disease frame: "a tireless toiler who spent all his waking hours trying to find a cure for people's ailments"; 95 the prophet in the scientific breakthrough frame; the 'reassurer' in a threat frame; the maverick: a devoted, stubborn and unpredictable scientist; and the ordinary mortal. ${ }^{96}$ This framing is partly expressed in the visual imagery that positions scientists, e.g., in a laboratory or, in contrast, at home. ${ }^{97}$

Haynes analogously distinguished seven stereotypes of scientists in Western literature and film: the evil alchemist, the noble scientist, the foolish scientist, the inhuman researcher, the scientist as adventurer, the mad, bad and dangerous scientist and the helpless scientist. ${ }^{98}$ She says that 'the good scientists are clearly in the minority". 99 Along the same lines, very recently seven prototypes of scientists were found in fiction and non-fiction media consumed by Dutch children: a genius, a genius wizard, a nerd, a puzzler, an adventurer, a wizard, a mad scientist and a misunderstood genius. ${ }^{100}$ Irrespective of the differences between these stereotypes, they all have in common that tend to be at odds with the image of scientists that provide, as experts, rational arguments to an issue. 


\section{Objective}

The literature review suggests that the deliberative quality of both TV news and science reporting may be relatively low. In this study, we look more closely at one interesting and promising but under-investigated crossroad of TV news and science reporting, namely general-interest public $T V$ news in which scientists appear as sources. Interesting, because TV news is an important source of public information and an important channel for science communication, and general interest items might provide welcome channel for scientists to communicate relevant findings and attract attention to their trade. Promising, because the quality of public TV news is generally expected to be relatively high. This suggests that scientists may be well positioned to add a critical measure of substantiated arguments and balanced judgements to these news items. However, available studies warn that scientists may be subordinated to the modern media logic, even in public news. Their contribution may have become embedded in journalist-centred stories in which scientists themselves appear as "opportune witnesses"101 in the "instrumental actualization"102 of journalists.

To explore this issue, we ask three sets of research questions. First, we define the base line for our study: How frequently do scientists appear as sources in public TV news items, what topics do they cover, and what is their academic background? Next, we assess the contribution of scientists: What type of information do they contribute? Is their contribution explicitly based on research? And how are scientists positioned in the item, what role do they play? Thirdly, we assess the discursive quality of public TV news items in which scientists appear. How is the item framed, and to what extent are different views and arguments exchanged? By answering these questions, we aim to provide a preliminary assessment of the discursive contribution of scientists to public TV news.

\section{Methods}

This study presents a first empirical take on the deliberative quality of public TV news items in which scholars appear as sources. This requires an exploratory approach where we build upon an inductive content analysis of news broadcasts from five public broadcasters in Western Europe.

\section{Sample}

We focus on the most important daily news casts from five public broadcasters in Western Europe, as cases where deliberative quality might be relatively high. The most important daily news cast is the news cast at prime time (between $19.00 \mathrm{~h}$ and $22.00 \mathrm{~h}$ ) from the most important network of the country, which attracts a relatively large audience. Excluding broadcasts from countries that are not readily accessible to us in terms of transmission or language, we analysed items from Het Journaal (broadcasted by VRT, Belgium), Der Tagesschau (ARD, Germany), NOS Journaal (NOS, The Netherlands), $B B C$ News (BBC, United Kingdom) and ARTE Info (Arte, 
Germany/France). This sample is not representative for the whole of Europe. Missing are in particular countries from the North (the Scandinavian countries, where news consumption is exceptionally high), the South (Mediterranean countries, where news consumption tends to be lower), ${ }^{103}$ and Eastern Europe (with its different history). But our sample can be considered representative for public TV news in (the middle of) Western Europe.

Following Riffe, Lacy and Fico, we taped news casts on two randomly chosen days per month for the years 2006 and 2007, to arrive at a representative sample of items broadcasted by the selected programmes. ${ }^{104} \mathrm{~A}$ few broadcasts could not be used due to technical problems, leaving 216 broadcasts with 3528 items. All these items were checked for the appearance of scientists. In the next step, we excluded all items in which no scientists appeared, to create our original dataset. Because of the small numbers of news items where scientists do play a role, we analyse two years of news programmes instead of one. Our final sample contains 55 items (28 from 2006, and 27 from 2007) that were analysed in depth. This is a small but representative sample, and suitable for an exploratory and partly qualitative study.

\section{Content analysis}

The content analysis entails three parts. First, three coders collected descriptive data: the duration and topic of the news item, the speaking time of the scientist, the presentation of scientist (name, position, institution and scientific discipline) and whether research findings were explicitly discussed or not. All these data were checked by one researcher.

Next, all 55 items in which scientists appeared were analysed qualitatively. Using the interpretative method of social semiotics, ${ }^{105}$ two analytical frameworks were developed to analyse the news items systematically with open coding. The first framework provides a factual description of news items. The unit of analysis is a single shot, defined as an uncut camera action. For every shot, the images and the relevant conversation are described. Relevant conversation is defined as the most salient statements of participants in the conversation per shot.

The second framework explores the substance of the item, focusing on three metafunctions central to social semiotics: representation (in our study: information and deliberative quality), orientation (the positioning of the scientist) and organisation (news frames). ${ }^{106}$ For each meta-function, a topic list was derived from the reviewed literature. These topics were then used as guiding principle for the analysis. This resulted in a second data matrix, providing a qualitative description of the substance and framing of items.

The interpretative analysis of the 55 news items in the second stage was done by one researcher. Seven randomly selected news items were also transcribed by a second coder to compare the interpretation. The results of qualitative analyses of these two independent coders were similar.

In the third part of the study the results of the descriptive and interpretative analyses were summarized in categorical and dichotomous variables. Inter-coder reliability for a 
random sample of $10 \%$ of the news items in this stage was good, summarized in a Holsti's Coefficient of Reliability score of .96. The analysis presented below builds upon the resulting final dataset.

\section{Results}

In 2006 and 2007, one or more scholars got speaking time in mere 1.5 per cent of news items. Overall, 58 scholars appear in these 55 items. They speak on average 27 seconds per item. That is 17 per cent of the 2.5 minutes an average item takes.

Item topic and experts' expertise. About a third of the items in which scholars appear (i.e., 16 of the 55 items) deal with health issues, for example flu or asthma. Another typical topic that triggers reporters to include scholars is science and technology. Six items in our dataset deal with such S\&T topics as the discovery of new animal species or Internet phone calls. In addition, scholars feature in items dealing with a range of domestic issues, (e.g., economics, environment, crime and politics; 24 items in total) or a similar range of issues in foreign countries (9 items). See Table 1 for an overview. These findings indicate that scientists (in public TV news programmes in our case countries) are more frequently invited to provide information or comment upon a range of social issues rather than scientific issues. But their overall appearance in general TV news items is limited.

\begin{tabular}{|l|r|r|}
\hline Topic & $\mathrm{n}$ & $\%$ \\
\hline Health & 16 & 29.1 \\
Science and technology & 6 & 10.9 \\
Domestic issues & 16 & 29.1 \\
Domestic politics & 1 & 1.8 \\
Foreign issues & 6 & 10.9 \\
Foreign politics & 3 & 5.5 \\
Crime & 3 & 5.5 \\
Economics & 4 & 7.3 \\
\hline Total & 55 & 100 \\
\hline
\end{tabular}

Table 1. Topic of news item with scholars; 2006-2007, all networks.

Two-thirds of the scholars appearing in news items (40 of 58) are employed by a university, 17 scholars work for other organizations, such as hospitals and independent research organizations. Information on their field of expertise, e.g., political science or marine biology, is provided for 28 scholars. The other 30 scientists are announced in general terms as scholars, professors or PhDs, without explicit reference to their particular fields.

If we look more closely at the information that is provided about the featuring scientist (including institutional affiliation), we discover that 13 scientists have a medical background and 10 come from the natural or technical sciences. We also 
encounter nine social scientists, four economists, one with a legal background, and one from the arts. Still, for one-third ( 20 scholars), the item gives us no clue as to what the scientific background of the featuring scholar is.

Expertise and topic are to some extent related. About half of the medical experts (7) comment on health issues, whereas all social scientists and economists contribute to domestic or foreign items. Remarkably, as much as seven experts with a technical or natural sciences background appear in domestic items, too. This shows that domestic items include a relatively wide variety of experts. S\&T items, instead, are discussed by medical, technical or natural scientists, and health issues are discussed by medical experts or scientists with unknown backgrounds.

Research-based contribution. The relatively general introduction of scholars as 'experts', without further information on their actual field, is to some extent compensated by references to research. Twenty scientists substantiate their interventions with references to specific studies. In most cases (18 scientists), this includes their own research. Especially medical experts tend to refer to (own) research. The majority of scientists (38), on the other hand, relies in their contributions (implicitly) on their general expertise.

In particular, we find that scholars that are announced in general terms, tend to base their interventions more frequently on (own) research. In contrast, scholars whose backgrounds are explicitly mentioned, rely less frequently on research. This suggests that there might be two ways for journalists to establish the credentials of invited experts: by emphasizing scholars' field of expertise, or by having them cite specific studies.

\section{The contribution of scientists}

The interpretative analysis suggests that scientists contribute in five ways to news items. First, they may provide an informed opinion, meaning that they assess situations and provide (professional) opinions. A second option is to explain, by offering background information, contextualizing an issue, or presenting a general analysis that is relevant to the issue at hand. Thirdly, scientists may provide a specific analysis of a problem that is at the heart of an item. Fourthly, scientists may add specific facts and figures, and finally, they may provide research results that are relevant to the topic of the news item. Of course, scientists may offer several kinds of information in one item.

In the studied news items, scientists provide most of the time an informed opinion (24 items), a general explanation (17 items) or both (5 items). Less frequently they provide research results (10 items), specific problem analyses ( 8 items), or facts (6 items). In about half of the cases, these more specific types of information are combined with a general assessment or explanation.

Role of the scientist. Scholars are never the main protagonist of a story in the news. In the vast majority of the news items $(82 \%)$, journalists tell the story. Scholars, the interpretative analysis suggest, play the role of advisor, discoverer or doctor in these 
items. As advisor, experts give practical or strategic advice to the audience or third parties. They play this role relatively frequently, in 28 items. Discoverers appear in 11 items. In these items, scientists are presented as researchers who discovered, for example, a cancer treatment. In another 11 items, scholars play a medical role. They are concerned with curing people or with negative health effects of products. In addition to these three main roles, we also found a more general role (in 8 items) in which experts give a general assessment from their professional or personal point of view. For example, in one item a professor appears as member of a jury that selected the happiest employee of the year.

Scientists appearing in the role of discoverer tend to provide research results; and most research results are provided by discoverers. Likewise, scientists that adopt the role of advisor or playing a general role tend to offer informed opinions; and most informed opinions are offered by advisors and generalists. Medical experts, on the other hand, tend to offer different types of information.

\section{Discursive quality}

The interpretative analysis shows that most items in which scholars appear have an episodic character (35 items or $64 \%$ ). In these items, issues are presented as specific if not isolated cases or issues. A sizeable minority of 20 items $(36 \%)$, on the other hand, can be classified as thematic items. These are items in which a topic is placed in an appropriate context, historically or otherwise.

The content of the news items can be further framed in various ways, independent of whether the item is thematic or episodic. The interpretative analysis, where we identified the main frame, suggests that many items are framed in terms of conflicts (22 items). Next follow progress and threat frames - frames that emphasize progress and breakthroughs in science (14 items), usually as solutions for human or societal problems; and frames that emphasize the problems or threats instead ( 9 items), either in connection with a scholarly assessment or referring to research that might provide a solution in the future. Also the economic consequences frame is used to some extent (in 6 items). Two other generic frames - the responsibility and human interest frames are seldom dominant in the items that were investigated (in 1 respectively 2 items).

Expert contribution. Finally, we assess the discursive quality of the contribution of the scientific experts. The interpretative analysis suggests distinguishing between four types of contributions. About half of the experts repeat, confirm, support or at best elaborate the main statement of the item (in 27 items). In about a quarter of the items (12), scientists contribute by nuancing statements of others. They add qualifying conditions or tone down claims that have been made earlier. Criticizing or rebutting statements occurs in 9 items. And additional perspectives or angles that were not mentioned in the item before, are introduced by scientists in 7 items.

Surprisingly, additional views presented by scientists are never complemented by facts, research findings or specific problem analyses. Scientists that introduce a new perspective do so by offering an informed opinion or a general explanation. Also 
scientists that criticize or nuance tend to contribute general opinions and explanations. Specific analyses, facts and/or research findings are presented in but 2 out of 9 items in which scientists criticize, respectively 4 out 12 items in which scientists nuance. This means that facts, research findings and/or specific problem analyses are offered primarily to support the argument of the journalist, but even then in less than half of the cases (13 of 27 items).

As far as the diversity of viewpoints is concerned, we found that in 6 items two views on a conflict were expressed and in 9 items even more than two views. Combined this makes 15 items (or 27\%) in which two or more views are presented. In other items, only one side of a conflict is presented ( 7 items) or — in most cases - no conflict at all was presented (33 items).

Remarkably, no relationship could be established between the journalistic framing of an item (episodic or thematic) and the likelihood that more views were presented. The number of views presented in an item therefore does not depend on the depth within which an issue is covered.

\section{Conclusions}

Scientific experts do not often act as visible sources in television news. In less than 2 per cent of the news items of five Western European public broadcasting organizations in 2006 and 2007, scientists appear.

The deliberative quality of these 55 news items turns out to be modest. On the positive side, we found that $36 \%$ of these items are thematic. This is considerably more than the $8 \%$ that Semetko and Valkenburg found for public and commercial TV news items in general, and similar to the $32 \%$ they found for newspaper items. ${ }^{107} \mathrm{We}$ also discovered that $27 \%$ of the items offers two or more views on an issue. This is twice as much as Cottle and Rai found for their sample of general TV news. ${ }^{108}$ And thirdly, experts add nuance, critique or different views in half of the items. This all contributes to the deliberative quality of public TV news items.

But we also noted that but $31 \%$ of the experts substantiated their interventions with findings from their own research. Likewise, scholars added specific information (problem analyses, facts, research findings) in but 35\% of the items. This means, in our view, that the deliberative potential of scholars is only used to some extent; and that scientists only occasionally succeed in using their role as sources to communicate scientific findings.

More specifically, we discovered that news item editors tend to selectively include but a few of the possible aspects that experts may contribute. Thus, TV news items either tend to explicate experts' scientific backgrounds or to include scientists that refer to their own research findings. Likewise, items feature scholars that either add specific analyses, facts or research findings, or that nuance, critique or add a different perspective. Only seldom do experts support their nuancing, criticizing or diversifying contribution with specific analyses or data. 


\section{A typology of scholars in news items}

Elaborating our findings, we construe a typology of three types of scholars that play different roles in news items. This typology integrates and extends findings from previous studies.

The first type is the guardian, appearing mostly in health items. These items emphasize threats or diseases and the guardian cares about the health of patients or the public. He contributes facts and research findings or gives context and background, sometimes on the basis of own research. Items can be episodic or thematic. They tend to present a single view on the issue and the guardian is included to confirm this main message.

The second type of scholar is the discoverer. This type of scholar appears in news items dealing with science and technology. Items tend to be episodic, emphasizing scientific discoveries and breakthroughs. The scholar reports on research findings, and sometimes gives background information. In most cases, the contribution of the scholar is related to his or her own research.

The third type of scholar can be labelled as the advisor. Advisors appear mainly in news items dealing with domestic or foreign issues. Items may be episodic or thematic, framing events in different ways (e.g., emphasizing economic consequences). Scholars mainly assess or explain an issue and give advice: to the public (more practical advice, in terms of do's and don'ts) or to governments or businesses (more strategic advice, in terms of policies or strategies). Again, in most cases the experts support and confirm the story line chosen by the journalist.

A small and interesting subgroup of these advisors appears in discursive items. These are mostly items about domestic issues. Experts add to the discursive quality of an item by debating or criticizing another point of view. But rather than offering facts or research findings to support their view, their role is generally limited to providing a professional assessment of the issue.

The three roles that we found are in line with earlier research. The guardian and the discoverer resonate with the public image of science. ${ }^{109}$ They contribute to typical good news stories about medical innovations ${ }^{110}$ or natural scientific discoveries, ${ }^{111}$ where they can also act as prophets or 'reassurers'. ${ }^{112}$ The advisor role, in turn, resonates with the more modern role of social scientists as expert commentators, ${ }^{113}$ who may be asked to discuss topics that are only tangentially related to their work. ${ }^{114}$

\section{Scholars and journalists}

These findings fit a more general trend of journalist-centred reporting. Journalists appear from our study as the conductors of news items in which scientists may appear. These journalists rather than the scientists determine the deliberative quality of the items. ${ }^{115}$ They embed scholars in particular roles, primarily to add authority to statements made by others in a bounded framework of media logic. There is not much room for scientists to contribute fact-based problem analyses or to argue diverging 
views on the basis of specific data or research results. Instead, scientists provide different views or arguments to support the main message of the item.

The findings show that there is ample room to improve the deliberative quality of TV news items, even on public TV channels in Western Europe. Of course, final conclusions require a formal comparison of items across TV channels and type of sources, involving more different kind of news items, countries and a longer time frame. For the time being, however, this study suggests that journalists and scientists, from their different backgrounds, may face the joint task of improving the deliberative quality of TV news as main source of information for general audiences.

\section{Notes and references}

1 Science reporter, in P. Conrad (1999), Uses of expertise: Sources, quotes, and voice in the reporting of genetics in the news, Public Underst. Sci. 8(4): 289.

2 E. Albaek, P.M. Christiansen and L. Togeby (2003), Experts in the mass media: Researchers as sources in Danish daily newspapers, 1961-2001, Journalism Mass Comm. 80(4): 937-48;

P. Verhoeven (2010), Sound-bite science: On the brevity of science and scientific experts in Western European television news, Sci. Commun. 32(3): 330-55.

3 C.M. Koolstra, J.W.M. Bos and I.E. Vermeulen (2006), Through which medium should science information professionals communicate with the public: television or the internet?, JCOM 5(3): A01, pp. $2-8$.

4 E.g., H.P. Peters (1995), The interaction of journalists and scientific experts: Cooperation and conflict between two professional cultures, Media Cult. Soc. 17(1): 31-48;

D. Rowe and K. Brass (2008), The uses of academic knowledge: The university in the media, Media Cul. Soc. 30(5): 677-98.

5 See note 2, E. Albaek, P.M. Christiansen and L. Togeby (2003);

A. Rich and R.K. Weaver (2000), Think tanks in the US media, Harv. Int. J. Press-Pol. 5 (4): 81-103.

6 E.g. M. Bucchi (1996), When scientists turn to the public: Alternative routes in science Communication, Public Underst. Sci. 5: 375-394;

Y. Tsfati, J. Cohen and A.C. Gunther (2011), The influence of presumed media influence on news about science and scientists, Sci. Commum. 33(2): 143-166.

7 E.g. D. Rowe and K. Brass (2008), note 4.

8 Ibid; see note 2, E. Albaek, P.M. Christiansen and L. Togeby (2003);

S. Dunwoody and M. Ryan (1987), The credible scientific source, Journalism Quart. 64(1): 21-27;

A.L. Roth (1998), Who makes the news? Descriptions of television news interviewees' public personae, Media Cult. Soc. 20(1): 79-107.

9 See note 6, M. Bucchi (1996).

10 E.g. D.L. Altheide and R.P. Snow (1991), Media worlds in the postjournalism era, Aldine de Gruyter, New York, U.S.A.

11 P. Verhoeven (2008), Where has the doctor gone? The mediazation of science in medical television programmes in the Netherlands, 1961-2000, Public Underst. Sci. 17: 461-472;

P. Verhoeven and B. Lops (2008), Sleutelen aan wetenschap op televisie, [Fiddling with science on television. A short history of science on Dutch public television; the case of medical and science journalism], Tijdschrift voor Mediageschiedenis [Journal for Media History] 11(1): 109-31.

12 See note 4, D. Rowe and K. Brass (2008); see note 8, S. Dunwoody and M. Ryan (1987).

13 See note 4, D. Rowe and K. Brass (2008).

14 See note 8, S. Dunwoody and M. Ryan (1987). 
15 See note 2, E. Albaek, P.M. Christiansen and L. Togeby (2003).

16 See note 3, C.M. Koolstra, J.W.M. Bos and I.E. Vermeulen (2006).

17 European Commission (2011), Media use in the European Union, Standard Eurobarometer 76, Directorate-General Communication, Brussels, Belgium;

European Commission (2012), Media use in the European Union, Standard Eurobarometer 78, Directorate-General Communication, Brussels, Belgium.

18 R. van der Wurff and K. Schönbach (2012), Publieke verwachtingen van journalistieke accountability. Hoe denken Nederlanders over de verantwoordelijkheid van de journalistiek [Public expectations of journalistic accountability. How the Dutch think about journalistic responsibility], ASCoR, Amsterdam, Netherlands.

19 J.N. Druckman (2005), Media matter: How newspapers and television news cover campaigns and influence voters, Polit. Commun. 22(4): 463-81;

G.J. Hansen and W.L. Benoit (2007), Communication forms as predictors of issue knowledge in presidential campaigns: A meta-analytic assessment, Mass Commun. Soci. 10(2): 189-210.

20 E.g. K. Aarts and H.A. Semetko (2003), The divided electorate: Media use and political involvement, J. Poli. 65(3): 759-84;

J. Curran et al. (2009), Media system, public knowledge and democracy: A comparative study, Eur. J. Commun. 24(1): 5-26.

21 P. Norris and D. Sanders (2003), Message or medium? Campaign learning during the 2001 British general election, Polit. Commun. 20(3): 233-62.

22 See note 10.

23 E.g. J. Cohen (2002), Deliberation and democracy, in D. Estlund ed., Democracy, Blackwell Publishers, Malden, MA, U.S.A. pp. 77-106;

J. Habermas (2006), Political communication in media society: Does democracy enjoy still an epistemic dimension? The impact of normative theory on empirical research, Commun. Theor. 16(4): 411-426.

24 M.P. Porto (2007), Frame diversity and citizen competence: Towards a critical approach to news quality, Crit. Stud. Media Comm. 24(4): 303-21.

25 H. Wessler (2008), Investigating deliberativeness comparatively, Polit. Commun. 25(1): 1-22.

26 See note 1, P. Conrad (1999); see note 4, H.P. Peters (1995);

H.P. Peters (2002), Scientists as 'Public Experts', Tijdschrift voor Wetenschap, Technologie en Samenleving [Journal for Science, Technology and Society] 10 (2): 39-42.

27 See note 2, E. Albaek, P.M. Christiansen and L. Togeby (2003).

28 See note 4, D. Rowe and K. Brass (2008).

29 Also see note 4.

30 See note 4, D. Rowe and K. Brass (2008).

31 M.G. Pellechia (1997), Trends in science coverage: A content analysis of three US newspapers, Public Underst. Sci. 6 (1): 49-68.

32 M. Weigold (2001), Communicating Science, Sci. Commun. 23 (2): 164-193;

J. Suleski and M. Ibaraki (2010), Scientists are talking, but mostly to each other: a quantitative analysis of research represented in mass media, Public Underst. Sci. 19(1):115-125.

33 F. Heinderyckx (1993), Television news programmes in western Europe: a comparative study, Eur. J. Commun. 8(4): 425-450.

34 Leon, B. (2006), Science news as marginal topic, in J. Willems and W. Göpfert, Science and the Power of TV, pp. 101-114, VU University Press, Amsterdam, Netherlands.

35 M. Ramalho, C. Polino and L. Massarani (2012), From the laboratory to prime time: Science coverage in the main Brazilian TV Newscast, JCOM 11(2): A02, pp. 1-11.

36 See note 34;

B. Leon (2008), Science related information in European television: a study of prime-time news, Public Underst. Sci. 17(4): 443-460. 
37 Ibid;

S. de Cheveigné, and N. Cheddadi (1998), Science in European TV news, paper presented at PCST-5 conference: Science without frontiers, Berlin, Germany.

38 D. Nelkin (1995), Selling science: How the press covers science and technology, Freeman Press, New York, NY, U.S.A.

39 E.g. S.M. Friedman (1986), The journalist's world, in S.M. Friedman, S. Dunwoody and C.L. Rogers Scientists and journalists: reporting science as news, The free press, New York, U.S.A., pp. 17-41; S. Hilgartner (1990), The dominant view of popularization: conceptual problems, conceptual issues, Soc. Stud. Sci. 20: 519-539.

40 E.g. K.A. McComas and L.M. Simone (2003), Media coverage of Conflicts of Interest in Science, Sci. Commu. 24: 395-419;

D. Brossard (2009), Media, scientific journals and science communication: examining the construction of scientific controversies, Public Underst. Sci. 18: 258-274.

41 P. Weingart, A. Engels and P. Pansegrau (2000), Risks of communication: discourses on climate change in science, politics, and the mass media, Public Underst. Sci. 9: 261-283.

42 E.g. C. Smith (1996), Reporters, news sources, and scientific intervention: the New Madrid earthquake prediction, Public Underst. Sci. 5: 205-216.

43 J. Dearing (1995), Newspaper coverage of maverick science: creating controversy through balancing, Public Underst. Sci. 4: 341-361.

44 S. de Cheveigné (2006), Science and Technology on TV news, in J. Willems and W. Göpfert eds., Science and the Power of TV, VU University Press, Amsterdam, Netherlands, pp. 85-100; see note 35 ;

E. Weitkamp (2003), British newspapers privilege health and medicine topics over other science news, Public Relat. Rev. 29(3): 321-33.

45 F. Clark and D. Illman (2006), A longitudinal study of the New York Times science Section, Sci. Commun. 27: $496-513$.

46 W. Göpfert (1996), Scheduled science: TV coverage of science, technology, medicine and social science and programming in Britain and Germany, Public Underst. Sci. 5: 361-74;

P. Maeseele and L. Desmet (2009), Science on television: how? Like that!, JCOM 08(04): A03;

M. Lehmkuhl, C. Karamanidou, T. Mörä, K. Petkova, B. Trench and AVSA Research Team (2012), Scheduling science on television: A comparative analysis of the representations of science in 11 European countries, Public Underst. Sci. 21: 1002-1018.

47 See note 1, P. Conrad (1999).

48 H.J. Gans (1979), Deciding what's news, Pantheon Books, New York, U.S.A

49 J.B. Manheim (1998), The news shapers: strategic communication as a third force in news making, in D. Graber, D. McQuail and P. Norris eds., The politics of news: the news of politics, Congressional Quarterly Press, Washington, DC, U.S.A., pp. 94-109.

50 See note 4, H.P. Peters (1995).

51 Ibid., p. 38.

52 J.C. Besley and M. Nisbet (2011), How scientists view the public, the media and the political process, Public Underst. Sci. 22: 644-659.

53 Ibid; see note 4, D. Rowe and K. Brass (2008); see note 8, S. Dunwoody and M. Ryan (1987).

54 M. Maillé, J. Saint-Charles and M. Lucotte (2010), The gap between scientists and journalists: the case of mercury science in Québec's press, Public Underst. Sci. 19: 70-79.

55 T. Wilkie and E. Graham (1998), Power without Responsibility: Media Portrayals of Dolly and Science, Camb. Q. Healthc. Ethic. 7: 150-159.

56 S. Hornig Priest (2001), Cloning: A Study in News Production, Public Underst. Sci. 10: 59-69.

57 R. Holliman (2004), Media coverage of cloning: a study of media content, production and reception, Public Underst. Sci. 13: 107-130. 
58 M. Bourdaa, J.P. Konsman, C. Sécail, T. Venturini and I. Veyrat-Masson (in press), Does television reflect the evolution of scientific knowledge? The case of attention deficit hyperactivity disorder coverage on French television, Public Underst. Sci., DOI: 10.1177/0963662513484842.

59 S.M. Amberg and T.E. Hall (2010), Precision and Rhetoric in Media Reporting About Contamination in Farmed Salmon, Sci. Commun. 32(4): 489-513.

60 See note 54.

61 E.g. C. Smith (1996), Reporters, news sources, and scientific intervention: the New Madrid earthquake prediction, Public Underst. Sci. 5: 205-216.

62 See note 11, P. Verhoeven and B. Lops (2008).

63 D.C. Hallin (1992), Sound bite news: Television coverage of elections, 1968-1988, J. Commun. 42(2): 5-24.

64 J.G. Blumler and D. Kavanagh (1999), The third age of political communication: Influences and features, Polit. Commun. 16(3): 209-30;

K. Brants and P. van Praag (2006), Signs of media logic: Half a century of political communication in the Netherlands, Javnost - The Public 13(1): 25-40.

65 See note 11, P. Verhoeven and B. Lops (2008).

66 C. Michelle (2007), 'Human clones talk about their lives': Media representations of assisted reproductive and biogenetic technologies, Media Cult. Soc. 29(4): 644.

67 F.N. da Silva Medeiros and L. Massarani (2010), Pandemic on the air: a case study on the coverage of new influenza A/H1N1 by Brazilian prime time TV news, JCOM 09(03): A03, pp. 2-9.

68 J.E. Steele (1995), Experts and the operational bias of television news: The case of the Persian Gulf war, Journalism Mass Comm. 72(4): 799-812.

69 Ibid., p. 809.

70 Ibid., p. 806.

71 Ibid., p. 809.

72 C.H. de Vreese (2005), News framing: Theory and typology, Information Design Journal 13(1): 51-62.

73 D. Tewksbury et al. (2000), The interaction of news and advocate frames: Manipulating audience perceptions of a local public policy issue, Journalism Mass Comm. 77(4): 804-29.

74 R.M. Entman (1993), Framing: Toward clarification of a fractured paradigm, J Commun. 43(4): 52.

75 S. Iyengar (1996), Framing responsibility for political issues, Annals of the American Academy of Political and Social Science 546(1): 59-70.

76 Ibid., p. 62.

77 Ibid.;

H.A. Semetko and P.M. Valkenburg (2000), Framing European politics: A content analysis of press and television news, J. Commun. 50(2): 93-109.

78 H.A. Semetko and P.M. Valkenburg (2000), note 77; see also J.N. Cappella and K.H. Jamieson (1996), News frames, political cynicism, and media cynicism, Annals of the American Academy of Political and Social Science 546(1): 71-84.

79 See note 77, H.A. Semetko and P.M. Valkenburg (2000), p. 102.

80 W.A. Gamson and A. Modigliani (1987), The changing culture of affirmative action, in R.G. Braungart and M.M. Braungart eds., Research in political sociology, JAI Press, Greenwich, CT, U.S.A., p. 167.

81 See note 73, p. 806.

82 S. Cottle and M. Rai (2006), Between display and deliberation: Analyzing TV news as communicative architecture, Media Cult. Soc. 28(2): 163-89.

83 Ibid., p. 172.

84 Ibid., p. 173.

85 Ibid., p. 179.

86 M. Barua (2010), Whose issue? Representations of human-elephant conflict in Indian and international media, Sci. Commun. 32(1): 55-75. 
87 A. Donk, J. Metag, M. Kohring and F. Marcinkowski (2012), Framing emerging technologies: Risk perceptions of nanotechnology in the German press, Sci. Commun. 34(1): 5-29.

88 E.g. L.A. Marks, N. Kalaitzandonakes, L. Wilkins and L. Zakharova (2007), Mass media framing of biotechnology news, Public Underst. Sci. 16: 183-203;

P. Weingart, C. Salzmann and S. Wörmann (2008), The social embedding of biomedicine: an analysis of German media debates 1995-2004, Public Underst. Sci. 17: 381-396.

89 R.B. Carver, E.A. Rødland and J. Breivik (2013), Quantitative frame analysis of how the gene concept is presented in tabloid and elite newspapers, Sci. Commun. 35(4): 449-475.

90 R. van der Wurff (2012), Klimaatverandering als journalistieke uitdaging: een literatuur studie [Climate change as a journalistic challenge: A literature study], Tijdschrift voor Communicatiewetenschap [Journal of Communication Science] 40: 271-292.

91 See note 8, A.L. Roth (1998).

92 U. Schnabel (2003), God's formula and devil's contribution: Science in the press, Public Underst. Sci. 12: 255-259.

93 E. Väliverronen (2006), Expert, healer, reassurer, hero and prophet: Framing genetics and medical scientists in television news, New Genet. Soc. 25(3): 233-47.

94 Ibid., p. 238.

95 Ibid., p. 239.

96 D. Jacobi and B. Schiele (1989), Scientific imagery and popularized imagery: Differences and similarities in the photographic portraits of scientists, Soc. Stu. Sci. 19(4): 731-53;

See note 93.

97 M. Bucchi and R.G. Mazzolini (2003), Big science, little news: Science coverage in the Italian daily press, 1946-1997, Public Underst. Sci. 12: 7-24.

See note 93.

98 See note 92.

99 R. Haynes (2003), From alchemy to artificial intelligence: stereotypes of the scientist in Western literature, Public Underst. Sci. 12(3): 243-253, p. 244.

100 B. van Gorp, E. Rommes and P. Emons (in press), From the wizard to the doubter: Prototypes of scientists and engineers in fiction and non-fiction media aimed at Dutch children and teenagers. Public Underst. Sci., DOI: 10.1177/0963662512468566.

101 L.M. Hagen (1993), Opportune witnesses: An analysis of balance in the selection of sources and arguments in the leading German newspapers' coverage of the census issue, Eur. J. Commun. 8(3): 317-43.

102 H.M. Kepplinger, H. B. Brosius and J.F. Staab (1991), Instrumental actualization: A theory of mediated conflicts, Eur. J. Commun. 6(3): 263-90.

103 K.E. Gustafsson and L. Weibull (1997), European newspaper readership: Structure and development, Communications 22(3): 249-97.

104 D. Riffe, S. Lacy and F.G. Fico (2005), Analysing media messages: Using quantitative content analysis in research, LEA, Mahwah, NJ, U.S.A.

105 R. Iedema (2001), Analysing film and television: A social semiotic account of 'hospital: An unhealthy business', in T. van Leeuwen and C. Jewitt eds., Handbook of visual analysis, Sage, London, U.K., pp. 183-204.

106 Ibid.

107 See note 77, H.A. Semetko and P.M. Valkenburg (2000).

108 See note 82 .

109 J. Durant, G. Evans and G. Thomas (1992), Public understanding of science in Britain: The role of medicine in the popular representation of science, Public Underst. Sci. 1(1): 161-82.

110 E.F. Einsiedel (1992), Framing science and technology in the Canadian press, Public Understanding of Science, 1(1): 89-101.

111 See note 38.

112 See note 93; see note 96, D. Jacobi and B. Schiele (1989). 
113 See note 2, E. Albaek, P.M. Christiansen and L. Togeby (2003).

114 See note 8, S. Dunwoody and M. Ryan (1987).

115 See also K. Brants (2005), Who's afraid of entertainment, in D. McQuail, P. Golding and E. de Bens eds., Communication theory and research, Sage, London, U.K., pp. 103-117;

D.A. Graber (1994), The infotainment quotient in routine television news: A director's perspective, Discourse \& Society 5(4): 483-504;

see note 66 ;

see note 11, P. Verhoeven and B. Lops (2008).

\section{Authors}

Richard van der Wurff is researcher at The Amsterdam School of Communication Research ASCoR, University of Amsterdam. E-mail: r.j.w.vanderwurff@uva.nl.

Piet Verhoeven is researcher at The Amsterdam School of Communication Research ASCoR, University of Amsterdam. E-mail: P.Verhoeven@uva.nl.

Maite Gadellaa participated in the research project when she was a student enrolled in the Master's Programme of the Graduate School of Communication at the University of Amsterdam. E-mail: maitegadellaa@gmail.com.

How TO CITE: R. van der Wurff, P. Verhoeven and M. Gadellaa, "Scientists and deliberativeness of European public television news", JCOM 12(03) (2013) A02. 